\title{
Multivariate statistical approaches to benthic macroinvertebrates and water quality for farming impact assessment in Selangor River, Malaysia
}

Nadeesha Dilani Hettige

Universiti Putra Malaysia

Rohasliney Binti Hashim ( $\square$ rohasliney@upm.edu.my )

Universiti Putra Malaysia

Zulfa Hanan Ash'aari

Universiti Putra Malaysia

Ahmad Abas Kutty

Universiti Kebangsaan Malaysia

Nor Rohaizah Jamil

University Putra Malaysia: Universiti Putra Malaysia

Keywords:

Posted Date: February 12th, 2021

DOI: https://doi.org/10.21203/rs.3.rs-166744/v1

License: (c) (i) This work is licensed under a Creative Commons Attribution 4.0 International License.

Read Full License 


\section{Abstract}

The authors have requested that this preprint be removed from Research Square. 